\title{
Maximum Obtainable Efficiency For Engines And Refrigerators Based On The Stirling Cycle
}

\author{
Carlson, H; Commisso, Marcello Benito; Lorentzen, Bent
}

Published in:

Proceedings of the 25th Intersociety Energy Conversion Engineering Conference

Publication date:

1990

Document Version

Publisher's PDF, also known as Version of record

Link back to DTU Orbit

Citation (APA):

Carlson, H., Commisso, M. B., \& Lorentzen, B. (1990). Maximum Obtainable Efficiency For Engines And Refrigerators Based On The Stirling Cycle. In Proceedings of the 25th Intersociety Energy Conversion Engineering Conference (Vol. Volume 5, pp. 366-371). IEEE.

\section{General rights}

Copyright and moral rights for the publications made accessible in the public portal are retained by the authors and/or other copyright owners and it is a condition of accessing publications that users recognise and abide by the legal requirements associated with these rights.

- Users may download and print one copy of any publication from the public portal for the purpose of private study or research.

- You may not further distribute the material or use it for any profit-making activity or commercial gain

- You may freely distribute the URL identifying the publication in the public portal 


\title{
MAXIMUM OBTAINABLE EFFICIENCY FOR ENGINES AND REFRIGERATORS BASED ON THE STIRLING CYCLE
}

\author{
H. Carlsen, M.B. Commisso, B. Lorentzen
}

The Technical University of Denmark DK-2800 Lyngby

\section{ABSTRACT}

The efficiency of the ideal stirling cycle assumes, that the cylinder volumes are isothermal and that the temperatures in the cylinder volumes are identical to the temperatures in the heat sink and the heat source. The efficiency is then identical to the efficiency of the Carnot cycle. However, in a real stirling machine the cylinder volumes are nearly adiabatic instead of isothermal, and the heat is added or removed in heat exchangers. Then the efficiency of a stirling cycle will always be smaller than for a carnot cycle even with ideal heat transfer in.regenerator and heat exchangers.

Especially for stirling based refrigerators, which have been discussed recently as an alternative to refrigerators using CFC-gases, the maximum obtainable coefficient of performance is important.

Based on a simplified stirling cycle with ideal heat exchangers and regenerators, the maximum possible efficiency and dimensionless output for a stirling cycle as a function of dead volume, phase angle and temperatures in heat sink and heat source are calculated and compared with the efficiency of the carnot cycle. Also the influence of heat transfer in the cylinder volumes is analyzed, and the effect of "isothermalizers" are discussed.

\section{INTRODUCTION}

The stirling cycle is a closed cycle, were the working medium, which is a gas, is expanded and compressed at different temperatures. In the idealized cycle, expansion and compression are isothermal. Expansion and compression take place in separate cylinder volumes as shown in fig. 1a. Heat is added from the heat source in the expansion volume at the temperature $T_{E}$ and removed from the compression volume to the heat sink at the temperature $T_{c}$.

As the temperatures are different in the two cylinder volumes, heat is stored in a regenerator. When the gas flows from the hot volume to the cold volume heat is stored. This heat is used for heating the gas, when it flows back from the cold to the hot volume.

The stirling cycle can be used for an engine and for a refrigerator as well. If regeneration in the regenerator is perfect and all losses are assumed zero, the ideal stirling cycle has the same efficiency as the Carnot cycle. This requires that the cylinder volumes are isothermal and that there is no temperature difference between the gas in the cylinder and the heat sink and heat source respectively.

\section{SYMBOLS}

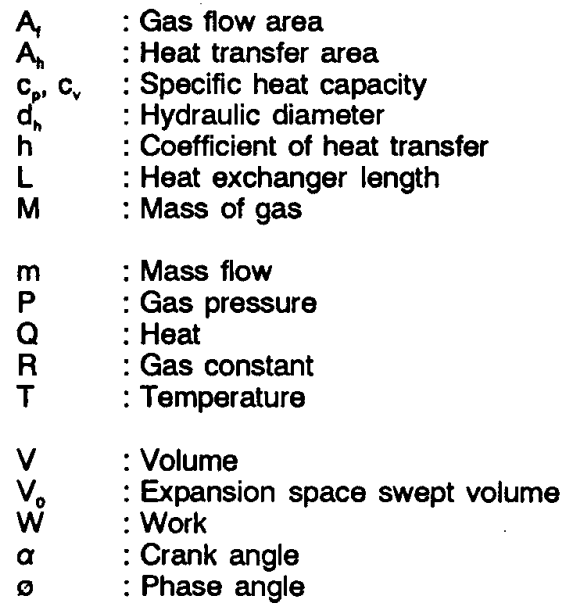

Dimensionless variables

\begin{tabular}{|c|c|}
\hline $\begin{array}{l}\text { COP } \\
\text { COP } \\
\text { NTU } \\
\text { Pr } \\
\text { St } \\
n \\
n_{c}\end{array}$ & $\begin{array}{l}\text { : Coefficient of performance } \\
\text { : Carnot-COP } \\
\text { : Number of transfer units } \\
\text { : Prandtl number } \\
\text { : Stanton number } \\
\text { : Efficiency } \\
\text { : Carnot-efficiency }\end{array}$ \\
\hline $\begin{array}{l}p \\
q \\
\tau \\
v \\
f \\
w\end{array}$ & $\begin{array}{l}\text { : Pressure } \\
\text { : Heat } \\
\text { : Temperature } \\
\text { : Volume } \\
\text { : Volume ratio } \\
\text { : Work }\end{array}$ \\
\hline
\end{tabular}

Indices

$\begin{array}{ll}\text { C } & \text { : Compression volume } \\ \text { D } & \text { : Dead volume } \\ \text { E } & \text { : Expansion volume } \\ \text { H } & \text { : Heat exchanger volume } \\ \text { W } & \text { : Cylinder wall } \\ \text { tot } & \text { : Total volume }\end{array}$


the pressure is the same in all four volumes.

The efficiency will then be a function of heat exchanger temperatures, dead volumes and phase angle. The efficiency will also be a function of the heat transfer between gas and wall in the two cylinder volumes.

The consequence of the simplifications is that the only losses compared to the ideal stirling cycle are due to the non isothermal cylinder volumes. If the wall temperature in the cylinder volumes is specified identical to the temperatures in the respective heat exchangers and the NTU-number in the cylinder volumes approaches infinity, the efficiency will approach the Carnot efficiency, and heat and work will approach the values calculated from the Schmidt analysis.

If data from a real engine or refrigerator are used, the re generator dead volume must be divided into two volumes, which are added to the hot and cold heat exchanger dead volumes respectively. The division must be made so that the volume and mass of gas in the regenerator are unchanged.

The mass, temperature and pressure of the gas in the four volumes are calculated from the first law of thermodynamics and the law of continuity by means of a computer program which solves the differential equations. Heat and work are found by integration, and the overall error can be checked from the energy balance.

\section{DIMENSIONLESS GROUPS}

In order to make the results more general, the variables are made dimensionless. The expansion space swept volume $V_{0}$ and heat exchanger temperature $T_{E}$ are used as a reference. The total mass of gas $M_{\text {tot }}$ is also used as a reference.

The main advantage is that the number of variables is reduced considerably. The dimensionless input and output variables to the computer program are defined below.

\section{INPUT VARIABLES:}

Temperature:

Temperature ratio: $\tau=T_{C} / T_{E}$

Cylinder wall, expansion space: $\tau_{W E}=T_{W E} / T_{E}$

Cylinder wall, compression space: $\tau_{w c}=T_{w d} / T_{c}$

Volume:

Volume ratio: $f=\frac{\text { compression space swept volume }}{\text { expansion space swept volume }}$

Expansion space dead volume: $V_{D E}=V_{D E} N_{0}$

Compression space dead volume: $v_{D C}=V_{D C} N_{0}$

Isothermal heat exchanger volume, expansion: $\mathrm{V}_{\mathrm{HE}}=\mathrm{V}_{\mathrm{HE}} N_{\mathrm{O}}$

Isothermal heat exchanger volume, compression: $V_{\text {HC }}=V_{\text {HC }} N$
Other variables:

Number of transfer units, expansion cylinder: $\mathbf{N T U}_{E}$ Number of transfer units, compression cylinder: $N_{T} U_{c}$ Phase angle : $\varnothing$

Heat capacity ratio: $k=c_{\nu} / c_{v}$

\section{OUTPUT}

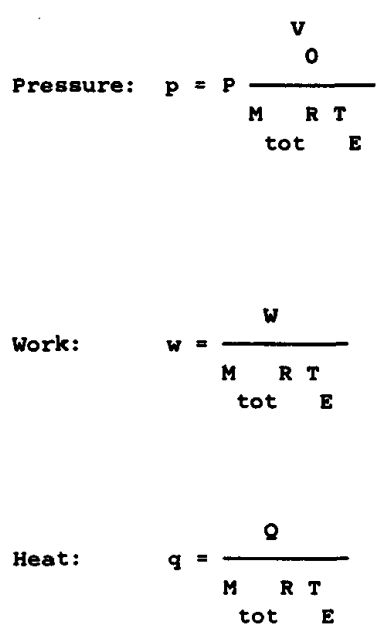

The variable volumes are expressed by the following equations:

Dimensionless expansion volume:

$v_{E}=0.5(1-\cos \alpha)+v_{D E}$

Dimensionless compression volume:

$v_{C}=0.5 f(1-\cos (\alpha-\varnothing))+v_{D C}$

The NTU-number is defined from the following equation:

NTU $=\frac{h h_{h}}{m c_{p}}$

The NTU-number has been used instead of $h A_{h}$ as a parameter for several reasons. Normally the NTU-number is related to heat exchangers, but if the heat transfer in the cylinder volumes is increased considerably, it is necessary to design the cylinder volumes as a heat exchanger. The mass flow rate into and out of the cylinder volume will then be important for the heat transfer. Another reason is that a large and constant value of heat transfer causes numerical problems when the mass of gas in the cylinder volume is small as in the top dead point. Furthermore, a comparison between results with constant NTU-number and constant $h$ $A_{h}$ shows that the difference is small.

\section{STIRLING MACHINE REFERENCE DATA}

As the computer program runs fast even on a IBM AT type personal computer it is possible to investigate the influence 
In real highperformance stirling machines, heat exchange between the working gas and the walls in the cylinder volumes is insufficient to transport the heat between the working gas and the surroundings. Therefore, heat exchangers are added between the cylinder volumes and the regenerator as shown in figure $1 b$.

A)

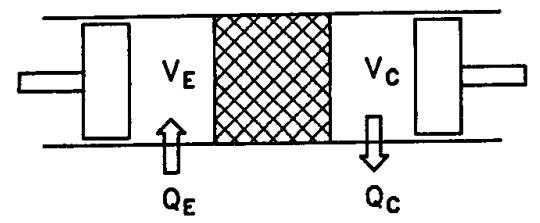

B)

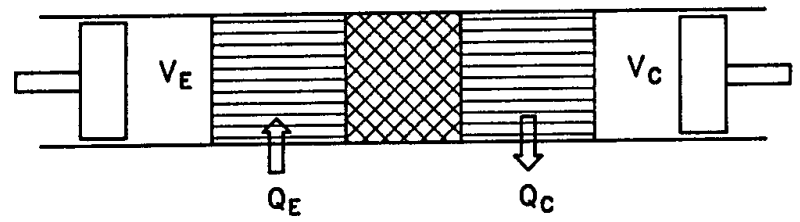

Figure 1: Stirling machine consisting of a) two variable cylinder volumes separated by a regenerator and b) with two heat exchangers included.

As a consequence of the poor heat transfer in the cylinder volumes in high performance stirling machines, the cylinder volumes are nearly adiabatic instead of isothermal. There fore the maximum obtainable efficiency is lower for the stirling cycle, even if all losses are assumed zero. The smaller the temperature difference between the heat sink and heat source is, the larger the reduction in efficiency will be compared to the Carnot efficiency.

For stirling based refrigerators, which have been discussed recently as an alternative to refrigerators using CFC-gases, the maximum obtainable coefficient of performance (COP) is important. In a refrigerator the temperature difference between heat sink and source are small compared to an engine, and the penalty from adiabatic cylinder volumes becomes unacceptable. Therefore it is important, especially for stirling refrigerators, to investigate the possibilities for increasing heat transfer in the cylinder volumes in order to improve the actual cycle towards the ideal isothermal stirling cycle.

The isothermal process raises the question of "isothermalizers" as discussed by C.D. West [1] and W.R. Martini [2], who both look at a specific stirling engine. Their conclusions are very different, and a further discussion is necessary.

In this paper a dimensionless generalized investigation is made in order to calculate the maximum possible efficiency and work for the basic stirling cycle.

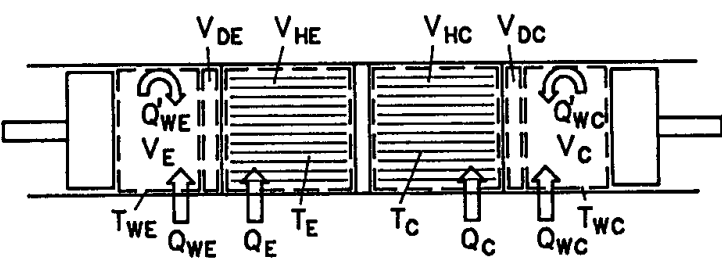

Figure 2: Simplified stirling machine cycle for the analysis.

\section{THE SIMPLIFIED STIRLING MACHINE}

In order to calculate the maximum possible efficiency and work, the stirling engine or refrigerator is simplified, so that it only consists of two variable cylinder volumes and two isothermal heat exchanger volumes as shown in figure 2. The isothermal heat exchanger volumes are separated by a regenerator without internal volume. The following assumptions are made:

Infinite heat transfer in the two heat exchangers, so that the temperature difference between the gas and the wall in the heat exchangers is zero, which means that the gas in the heat exchangers has the same temperatures as the heat sink and source respectively

The regenerator between the two heat exchangers has no internal volume.

Infinite heat transfer in the regenerator, so that heat losses are zero, which means that the gas flows into the regenerator with the temperature identical to one heat exchanger and flows immediately out in the other end with a gas temperature identical to the other heat exchanger.

Perfect mixing of gas in the two variable cylinder volumes.

Heat exchange between working gas and wall in the two cylinder volumes takes place at a constant NTU-number. The cylinder wall temperatures $T_{W E}$ and $T_{w c}$ are specified separately.

Flow losses in heat exchangers and regenerator are assumed zero.

Frictional losses are eliminated.

The working gas acts as a perfect gas with $c_{p}$ and $\mathrm{C}_{\mathrm{v}}$ independent of temperature.

Sinusoidal variation of the two cylinder volumes.

The assumptions result in a momentary change in gas temperature when the gas flows between the heat exchangers and the cylinder volumes and from one heat exchanger through the regenerator to the other heat exchanger. Also 
of a large number of parameters on output and efficiency. However, because of lack of space only the most important results are shown here.

A set of reference data has been used. These data are based on common practice for stirling machines, except for the refrigerator phase angle, which is chosen as a compromise between cooling effect and efficiency:

$\begin{aligned} \text { Temperature ratio, engine: } & \tau & =0.33 \\ \text { refrigerator: } & \tau & =1.18\end{aligned}$

Heat capacity ratio: $k=1.4$

Volume ratio: $v=1.0$

Expansion space dead volume: $v_{\mathrm{DE}}=\mathbf{0 . 0 5}$

Compression space dead volume: $v_{\mathrm{DC}}=\mathbf{0 . 0 5}$

Isothermal heat exchanger volume, expansion: $V_{\mathrm{HE}}=0.5$

Isothermal heat exchanger volume, compression: $V_{\mathrm{HC}}=0.5$

$$
\begin{aligned}
\text { Phase angle, engine: } & \emptyset=120^{\circ} \\
\text { refrigerator: } & \varnothing=145^{\circ}
\end{aligned}
$$

The results are calculated as a function of the NTU-number, which has the same value in the compression and expansion cylinder volumes.

The engine specifications corresponds to a heater temperature at $700 \mathrm{C}$ and a cooler temperature at $50 \mathrm{C}$, and the pressure ratio is approximately 2.0. The refrigerator temperature ratio corresponds to a hot end temperature at 40 $\mathrm{C}$ and a cold end temperature at $-8 \mathrm{C}$. Hydrogen and air has a heat capacity ratio of 1.4 , while helium have 1.67 .

\section{THE EFFECT OF "ISOTHERMALIZERS"}

According to the discussion about the influence of "isothermalizers", two different cases are first discussed. The two cases are:

A) Cylinder wall temperatures $T_{W E}$ and $T_{W C}$ are identical to the expansion and compression space heat exchanger temperatures $T_{E}$ and $T_{C}$ respectively. For increased NTU-number in the cylinder volumes, the cylinder wall will take care of a part of the heat exchange between the gas and the surroundings.

B) Cylinder wall temperatures $T_{W E}$ and $T_{W C}$ are calculated, so that net heat transfer between the gas in the cylinder volumes and the surroundings is zero for a complete cycle. For increased NTU-number the cylinder volumes will be more isothermal, but they will NOT take care of any heat exchange between the gas and the surroundings.

In both cases the wall temperature $T_{w}$ is constant over the cycle. Only the gas temperature in the cylinder volume changes periodically.

The consequence of $A$ ) is, that the cylinder volumes must be made as a part of the heat exchanger in order to main- tain the cylinder wall temperatures $T_{W E}$ and $T_{W C}$ identical to the respective heat exchanger temperatures $T_{E}$ and $T_{C}$.

As a consequence of $B$ ) there will be a temporary heat transfer between gas and cylinder wall as illustrated in figure 2 by $Q_{W E}^{\prime}$ and $Q_{W C}^{\prime}$, but the net heat transfer $Q_{\text {WE }}$ and $\mathrm{Q}_{\text {wc }}$ over a cycle is zero. Most high performance stirling engines are very close to $B$ ), as the cylinder volumes are separated from the heat exchangers.

As it is difficult to design the pistons in a stirling machine as a part of the heat exchangers, the surface of the piston, which is a part of the cylinder volume, will always act as case B).

When the NTU-number is zero, the two cases are identical. When the NTU-number approaches infinity the efficiency for type A) approaches the Carnot-efficiency and the work approaches the value calculated from the Schmidt analysis.

For the type B) machine the gas temperature will be isothermal when the NTU-number approaches infinity, but the efficiency will not approach the Carnot-efficiency, as the gas temperature is different, when it flows into and out of the cylinder volume.

In figure 3 the COP relative to the $\mathrm{COP}_{\mathrm{C}}$ and the dimensionless cooling rate are shown as a function of the cylinder wall NTU-number for a stirling refrigerator. From the figure is seen that the COP's are identical for the type A) and type B) refrigerator with adiabatic cylinder volumes $(\mathrm{NTU}=0)$.

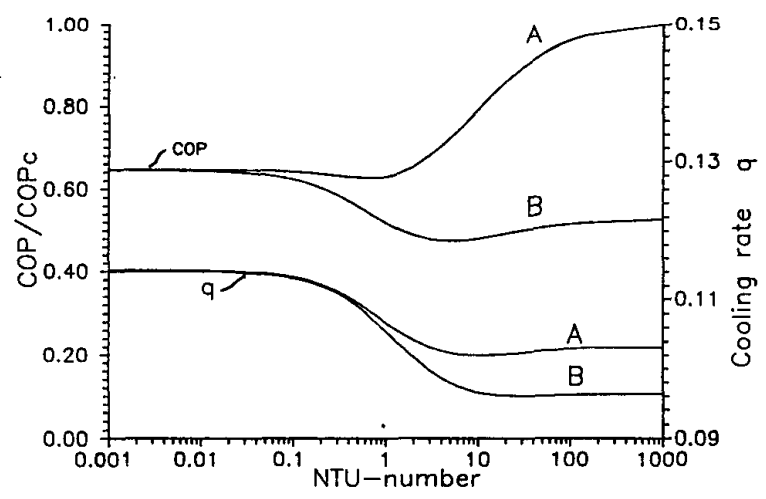

Figure 3. $\mathrm{COP} / \mathrm{COP}_{\mathrm{c}}$ and dimensionless cooling rate as a function of the cylinder wall NTU-number for a stirling refrigerator.

When the NTU-number is increased the COP DECREASES. For a further increase in the NTU-number, the COP for the type $\mathrm{A}$ ) refrigerator approaches $\mathrm{COP}_{\mathrm{C}}$. For the type B) refrigerator COP decreases below $50 \%$ of the COP When the NTU-number approaches infinity, the COP only increases to a value close to the value for adiabatic cylinders.

The cooling rate decreases for increasing NTU-number. A minimum is obtained between 10 and 100 , but the cooling 
rate for large NTU-numbers is $10 \%$ to $15 \%$ lower than for the adiabatic refrigerator with NTU $=0$.

Figure 4 shows the efficiency relative to the Carnot efficiency and the dimensionless work as a function of the NTUnumber for a stirling engine.

The same tendency is observed as for the refrigerator, except that the difference between the type A) and the type B) machine is smaller, because of the larger temperature difference between hot and cold space. There is a significant minimum for efficiency and work, and the type B) engine has $10 \%-20 \%$ lower efficiency and work pr. cycle compared to the type A) engine for large NTU-numbers.

For other stirling machine specifications the results are varying, but the tendency is the same. It can therefore be concluded, that "isothermalizers", which are NOT integrated with the heat exchangers will decrease efficiency and work pr. cycle.

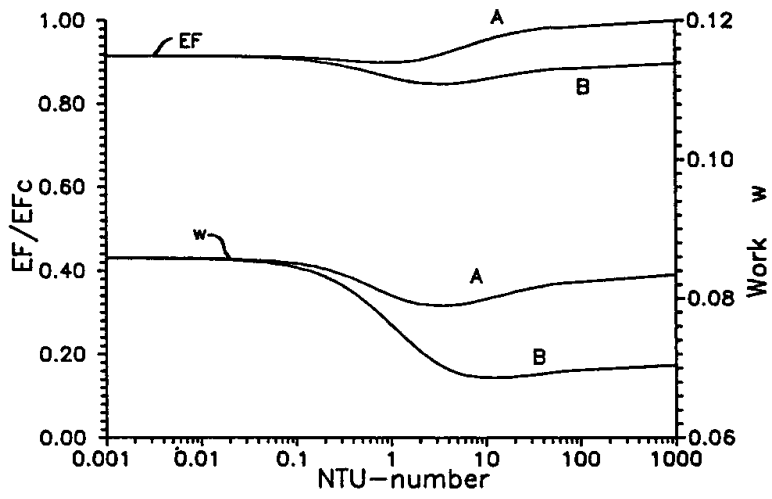

Figure 4. Efficiency/Carnot-efficiency and dimensionless work as a function of the NTU-number for a stirling engine.

If "isothermalizers" are to be used, they must be very effective, since the results here indicates that for typical heat transfer conditions they will, in fact, lower efficiency. If isothermalizers are introduced into a specific design with efficient heat exchangers the work pr. cycle will, normally, be decreased.

The results agree with results from C.D. West as described in [1]. Of course the present results are only valid for stirling machines with external heat exchangers. If there are no external heat exchangers, the heat must be transferred in the cylinder volumes, or the cycle will fail.

That is a part of the problem, when the results are compared to the results of W.R. Martini as described in [2]. Here there are no external heat exchangers, and when the heat transfer in the cylinder volumes decreases, the regenerator has to act as a sort of heat exchanger. The validity of the results is therefore limited to stirling engines with heat transfer in the cylinder volumes instead of in separate heat exchangers and can not be compared to the results here and in [1].

\section{GENERAL RESULTS}

As the most favorable results are found for the type A) cylinder volume model, this model is used for the parametric variation. Only results for different temperature ratios $\tau$ are shown here because of lack of space. The results can be used as a reference for maximum possible efficiency and output.

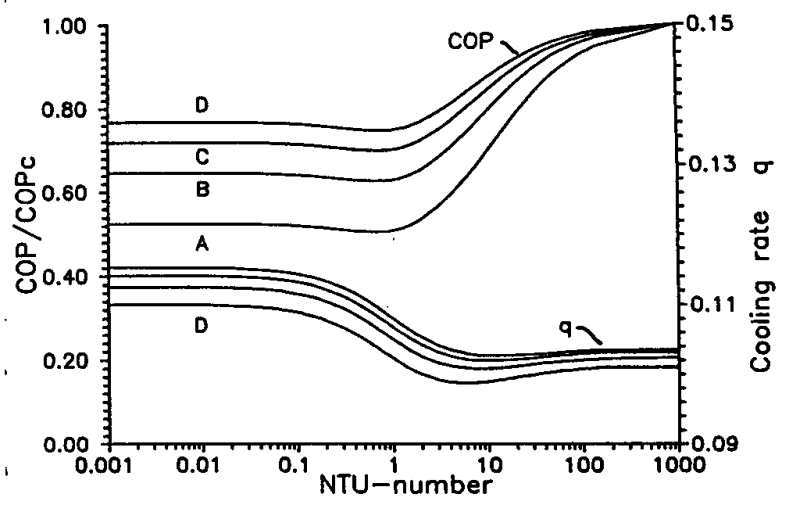

Figure 5. Stirling refrigerator $\mathrm{COP} / \mathrm{COP}_{\mathrm{c}}$ and cooling effect $q_{E}$ as a function of the NTU-number at four different temperature ratios $A: 1.10, B: 1.18, C: 1.28, D: 1.42$.

Figure 5 contains results for the stirling refrigerator as described previously. The figure shows COP/COP-Carnot and dimensionless cooling rate $q_{E}$ as a function of the NTUnumber in the cylinder volume at four different temperature ratios.

Figure 6 contains results for the stirling engine as described previously. The figure shows relative efficiency $n \mu_{c}$ and dimensionless work as a function of the NTU-number in the cylinder volumes at four different temperature ratios.

If the NTU-number for the heat transfer in the cylinder volume is compared to the heat transfer in a heat exchanger, the following considerations can be made:

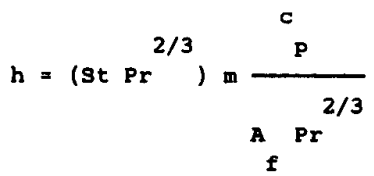

This equation is introduced in the NTU-number expression:

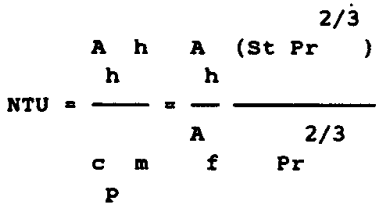




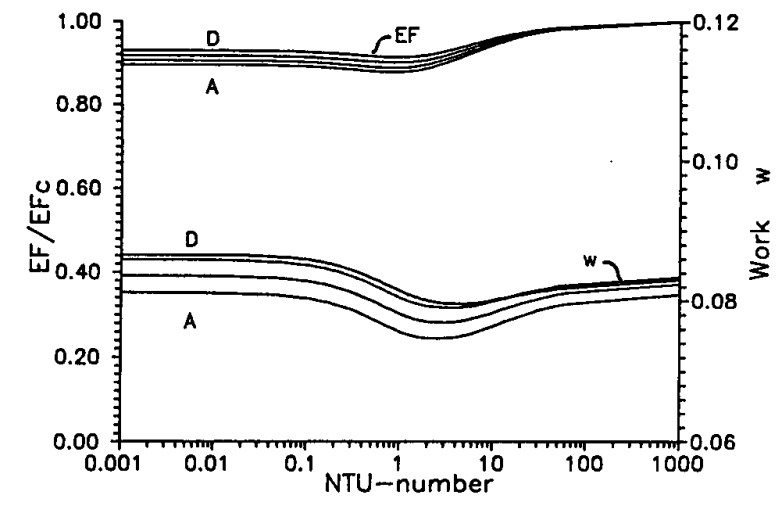

Figure 6. Stirling engine efficiency $n / n_{c}$ and dimensionless work as a function of the NTU-number at four different temperature ratios $\mathrm{A}: \mathbf{0 . 4}, \mathrm{B}: \mathbf{0 . 3 7}, \mathrm{C}: \mathbf{0 . 3 3}$, D: 0.28 .

Inserting the hydraulic diameter $d_{n}=4 L A_{N} / A_{n}$ we get:

$\mathrm{NTU}=4 \frac{\mathrm{L}}{\mathrm{d}} \frac{\left(\text { St }_{\mathrm{hr}}{ }^{2 / 3}\right)}{\operatorname{Pr}^{2 / 3}}$

From [3] it is seen, that the St $\mathrm{Pr}^{2 / 3}$ is nearly always between 0.002 and 0.02 . The Prandtl number for gases is approximately 0.7. A typical stirling heat exchanger has a $L / d_{h}=50$, which results in NTU-numbers between 0.5 and 5. For example, the cooler in the GPU-3 stirling engine has a NTU-number of 1.8 .

As it is more difficult to design a cylinder volume with efficient heat transfer than designing a heat exchanger, NTUnumbers in the cylinder volumes are likely to be below 5 . It might therefore be wiser to insulate the cylinder volumes than making "isothermalizers".

However, the results also show that a refrigerator with adiabatic cylinder volumes has a low COP compared to the Rankine cycle, which has a COP close to the Carnot cycle. That is despite a phase angle at $145^{\circ}$, which gives a high COP but a low specific cooling rate. If a stirling based alternative to the CFC-based refrigerator is going to be competitive, efficient heat transfer in the cylinder volumes is necessary.

\section{CONCLUSION}

An investigation based on a simplified stirling analysis of an idealized engine has been made. The only losses compared to the ideal stirling cycle are due to non isothermal cylinder volumes. The computer program based on the analysis can be used for the calculation of maximum possible efficiency and work for stirling refrigerators and engines.

The results show, that "isothermalizers", which are NOT integrated with the heat exchangers, will always decrease efficiency and work pr. cycle.

"Isothermalizers", which take part in the heat exchange between working gas and heat sink and source, must be very efficient, as they might otherwise decrease instead of increasing efficiency. The power per cycle will always be decreased compared to a machine with adiabatic cylinder volumes and efficient heat exchangers.

It is also shown that it is very difficult to design a refrigerator based on the stirling cycle, which has a competitive COP compared to conventional CFC-based refrigerators.

\section{REFERENCES}

[1] C.D. West: Stirling Machines - Adiabatic to Isothermal, 3rd International Stirling Engine Conference, 1986, ISEC 86-VI-67.

[2] W.R. Martini: Investigation of the Isothermalization of the Hot and Cold Gas Spaces using Numerical Analysis, 3rd International Stirling Engine Conference, 1986, ISEC 86-VII-43.

[3] W.M. Kays, A.L. London: Compact Heat Exchangers, McGraw-Hill Book Company, 1984. 